\title{
st \\ Albert Einstein: ciência, filosofia e política
}

Samuel Simon

\section{Ciência \& Ambiente}

Einstein

Universidade Federal de Santa Maria

Santa Maria, n. 3o, jan./jun. 2005, 182 págs.

O número 3 o da revista Ciência \& Ambiente oferece ao leitor brasileiro uma ótima oportunidade para conhecer vários aspectos do trabalho de Albert Einstein. A publicação insere-se nas atividades do Ano Mundial da Física, que comemorou em 2005 os 100 anos dos pioneiros trabalhos do cientista alemão. Físicos, filósofos e historiadores da ciência abordam neste número da revista, numa série de onze artigos, as várias contribuições de Einstein à física - não se limitando apenas às duas teorias da relatividade, a restrita, ou especial, e a geral-, além de sua atuação política. A série de artigos é acompanhada também por uma cronologia com os principais fatos da vida de Einstein.

Peter Galison escreve o primeiro artigo e apresenta uma tese bastante original: a definição de simultaneidade, uma das noções centrais da teoria da relatividade em sua formulação restrita, teve sua origem no contato de Einstein com o problema prático de sincronização de relógios na Europa do início do século xx. O autor inicia seu artigo lembrando um aspecto pouco examinado nos estudos que discutem o trabalho de 1905 de Einstein: o problema da assimetria na interpretação das equações de Maxwell. A invariância dos fenômenos resultantes do movimento relativo de bobinas e ímãs não compactuava com a assimetria presente na interpretação dessas equações. O problema, segundo Einstein, - nos lembra Galison - era que "não se prestou atenção suficiente ao fato de que a eletrodinâmica sempre dependeu da visão sobre a cinemática". Ou seja, o comportamento de relógios e réguas era importante quando se levava em conta movimentos relativos, pois nossos julgamentos são feitos sobre eventos simultâneos. E para se efetuar adequadamente essas medidas, a definição de simultaneidade era importante.

O final do século xix viu os esforços de relojoeiros importantes, na Suíça, sobretudo, serem recompensados. O tempo foi sincronizado por relógios elétricos, e mesmo o pai e o tio de Einstein trabalharam em mecanismos eletromecânicos sensíveis, 
semelhantes a relógios, que visavam medir o uso de eletricidade (há no artigo uma reprodução do cartaz que apresentava a fábrica dos Einstein). A sincronização de relógios era algo importante no final daquele século, pois erros nessa sincronização poderiam ser desastrosos para os trens que se cruzavam nos trilhos da Europa. E esse problema técnico pode ter sido decisivo, segundo Galison, para os raciocínios de Einstein sobre o problema do tempo nas teorias físicas, principalmente porque eram vistos inúmeros relógios coordenados no caminho até o escritório de patentes. Einstein mudou-se para a zona de tempo unificado em 15 de maio de 1905; nessa época, discutia intensamente com seu amigo e colega de escritório, M. Besso, sobre os problemas da teoria eletromagnética. Como o próprio Einstein relata, uma certa manhã ele nem saudou o amigo e foi dizendo: "Pode me dar os parabéns; resolvi completamente o problema. Uma análise do conceito de tempo foi minha solução. O tempo não pode ser definido em termos absolutos e há uma relação inseparável entre tempo e velocidade sinalizada". Apontando para o relógio da torre de Berna e, em seguida, para um relógio na torre em Muri, Einstein descreveu a sincronização dos relógios. Ou seja, a definição de simultaneidade era a chave para a solução do problema da relatividade do movimento.

Galison observa que, anteriormente a Einstein, Poincaré já havia introduzido relógios que eram coordenados por meio da troca de sinais luminosos. Em 1898, Poincaré escreve o artigo "La mesure du temps", que Einstein certamente conheceu através do livro Science et hypothèse, de 1902. Enquanto Poincaré identificava a busca pela sincronização a um problema de grande complexidade, cujas correções no mundo newtoniano seriam tão pequenas que a "necessidade teórica" teria de ser abandonada em favor da demanda por simplicidade, Einstein compreendia que essas mudanças levariam a uma física imensamente mais simples. Afastando um possível reducionismo tecnológico, as conclusões de Galison são basicamente duas. A primeira é a importância da definição de simultaneidade e sua relação histórica com o desenvolvimento técnico da sociedade européia. A segunda é que "penetrar em um mundo onde ocorria o triunfo do elétrico sobre o mecânico" significava estar simbolicamente ligado a sonhos de modernidade.

O segundo artigo, de Michel Paty, discute um outro tema caro a Einstein: a teoria quântica. $\mathrm{O}$ autor escolhe uma abordagem bastante original: as relações entre o conceito de campo contínuo e os quanta. Essa análise, segundo Paty, permite perceber uma separação bastante nítida: de um lado, a física do contínuo e, de outro, as propriedades atômicas. Empregando os termos de J. Bernoulli a propósito de Newton, o autor observa que é possível reconhecer, nesses dois campos, a marca de um estilo. Ou seja, há um "estilo científico" em Einstein que pode ser resumido em três etapas. Na primeira, a dimensão crítica acompanha a perspectiva de um acercamento preciso do objeto físico; na segunda, o pensamento crítico prepara uma construção teórica, segundo con- 
ceitos e princípios físicos; na terceira, as diferenças de abordagem teórica, em domínios diferentes, decorrem da idéia de uma relação de adequação, a mais exata possível, entre a teoria e os objetos investigados. Esse estilo contém, na verdade, duas atitudes que alguns autores tendem a separar. Paty observa, de maneira bem precisa, que essa dupla preocupação esteve presente desde o início, pois os três primeiros trabalhos mais importantes de 1905 tratam de assuntos diferentes. 0 primeiro, da energia atômica da matéria; o segundo diz respeito à energia da radiação luminosa e o terceiro, à relatividade dos movimentos na eletrodinâmica. E as duas abordagens estão presentes em momentos bastante cruciais do trabalho de Einstein: tão logo conclui as pesquisas sobre a relatividade geral em 1915, ele retoma, em 1916-1917, a teoria dos quanta; no período 1923-1925, retorna à teoria do campo. Este último tema parece ter ocupado com mais energia seus trabalhos a partir de 1927, embora se dedicasse simultaneamente ao problema quântico e ao problema do campo contínuo, em numerosos escritos mais gerais sobre física: Física e realidade, de 1936, Notas autobiográficas, de 1946 (publicado em 1949), Respostas aos críticos, de 1949, entre outros.

No que se refere aos estudos sobre o conceito de campo, Michel Paty observa que o fato de Einstein não compartilhar de uma "visão eletromagnética do mundo" pode ter sido importante para a crítica que vai operar na construção da teoria da relatividade. Na verdade, Einstein considerava que tanto a teoria eletromagnética quanto a mecânica clássica não eram absolutas e definitivas. A conclusão de Paty é clara: "a insatisfação com referência à teoria eletromagnética de então foi o ponto de partida do raciocínio de Einstein”. Gostaríamos, no entanto, de nossa parte, de observar que, na medida em que as equações exprimissem domínios bem estabelecidos de fenômenos da natureza, elas seriam um ponto de partida sólido para as futuras reformulações teóricas, como Einstein deixa claro em suas Notas autobiográficas em relação à transição da mecânica newtoniana à relatividade geral.

Atentando assim para a separação que leva em conta a especificidade dos fenômenos e o objeto estudado, constituiu-se, no caso do contínuo, uma reforma fundamental baseada em princípios teóricos e, no caso da teoria quântica, pelo menos nos primeiros trabalhos, um "ponto de vista" heurístico. Ou seja, embora a teoria da relatividade restrita tenha mudado nossas concepções sobre a natureza da luz, na medida em que "a luz não é mais concebida como estados de um meio hipotético", como escreve o próprio Einstein, ele admitia propriedades específicas não explicadas pela relatividade, como a dualidade característica dos fenômenos quânticos.

Paty conclui seu artigo apontando para um aspecto bastante relevante: o problema da unidade teórica. Se, por um lado, a relatividade geral era concebida como um avanço do qual não se podia recuar, por outro lado, a unidade baseada no continuum espaço-temporal parecia cada vez mais distante da mecânica quântica. Einstein estava, 
obviamente, ciente dessa dificuldade. Sua dúvida era se a mecânica quântica poderia servir de base para ir mais longe e se ela estava completa: estaria ela fornecendo uma representação unívoca de um sistema individual? Parece que Einstein nunca se convenceu dessa possibilidade.

No artigo seguinte, Aguinaldo Medici Severino e Abel Lassalle Casanave examinam uma passagem controversa na história da ciência: há uma precedência de Hilbert em relação a Einstein na formulação da teoria da relatividade geral? A pergunta se coloca porque Hilbert apresentou seu artigo cinco dias antes de Einstein; dela decorre outra pergunta ainda mais perturbadora: esse caso refletiria um "estilo" de Einstein, ou seja, sua "capacidade" de apropriar-se de idéias e trabalhos alheios?

Severino e Casanave iniciam o seu artigo lembrando que, durante certo tempo, a teoria foi denominada de teoria da relatividade Einstein-Hilbert. $\mathrm{O}$ argumento básico era que os dois autores haviam chegado independentemente às mesmas equações: Hilbert por uma construção axiomática derivada de um princípio variacional e Einstein em decorrência da generalização da teoria da relatividade restrita. A controvérsia persistiu por aproximadamente 80 anos e perdurou até 1990. A principal defesa da precedência de Hilbert é a de J. Mehra, no livro Einstein, Hilbert and the theory of gravitation. ${ }^{1}$ A tese central de Mehra, expõem Severino e Casanave, é que a contribuição de Hilbert foi fundamental para que a pesquisa de Einstein alcançasse êxito. Weyl foi possivelmente o primeiro, em 1918, a defender uma dupla paternidade da teoria, seguido por outros cientistas, como Pauli. Um dos pontos de defesa dessa tese é que Einstein cita, em 1916, certas observações de Hilbert.

No entanto, essa tese foi contestada em 1997 por L. Corry, J. Renne e J. Stachel no artigo "Decision in the Hilbert-Einstein priority dispute". ${ }^{2}$ Segundo esses autores, ocorreu justamente o contrário no que se refere à precedência: Hilbert baseou sua formulação da relatividade em uma vasta (e documentada) troca de correspondência com Einstein, que aponta que ele já havia obtido parte dos resultados, já submetidos à publicação. De fato, a precedência de Einstein parece incontestável por três razões. Primeiro, porque na correção da primeira prova do seu artigo, Hilbert cita o trabalho de Einstein submetido em 25 de novembro e publicado em 2 de dezembro de 1915; vale observar que esse é o trabalho que apresenta a teoria da relatividade geral em sua formulação praticamente definitiva. Segundo, porque na prova corrigida, em 6 de dezembro de 1915, Hilbert inclui a afirmação segundo a qual o tensor métrico foi inicialmente introduzido por Einstein. Finalmente, a prova decisiva: Hilbert reconhece que as equações diferenciais da gravitação obtidas por ele estão de acordo com a teoria da re-

1 Dordrecht, North Holland, 1974 .

2 Science, 278, p. 1270-3, 1997. 
latividade geral de Einstein. Se parece não haver dúvida da precedência de Einstein conforme a conclusão dos autores, não se pode negar a grandeza do trabalho de Hilbert, que estava interessado, sobretudo, nos aspectos matemáticos da geometria do espaço. Severino e Casanave nos apresentam uma historiografia de alto nível, pela análise feita e pela escolha do tema.

O quarto artigo, de Antonio Luciano Leite Videira, constitui-se numa apresentação didática das duas teorias da relatividade, a restrita e a geral. O leitor pouco familiarizado com esses trabalhos tem aqui uma boa oportunidade de acompanhar as idéias gerais que constituem os trabalhos pioneiros de Einstein. $\mathrm{O}$ autor inicia sua exposição afirmando que enquanto certas quantidades são invariáveis, como o número de átomos [em um gás isolado], outras dependem do movimento relativo, como a variação de frequiência de ondas sonoras e luminosas. Nesse sentido, um aspecto importante da teoria da relatividade restrita é a variação de certas quantidades, que dependem do movimento relativo dos referenciais; daí resultam a contração espacial e a dilatação temporal. No entanto, como bem observa o autor, o princípio de relatividade constituirá, ao lado da constância da velocidade da luz no vácuo, um dos pilares da relatividade restrita. Isso foi conseguido privilegiando as equações de Maxwell e mostrando as limitações da física newtoniana.

A partir da equivalência entre massa e energia, oriunda da relatividade restrita, o passo para a teoria da relatividade geral estava dado: a energia também é atraída por matéria. Essa noção abrirá caminho para a formulação da relatividade geral, mas dois aspectos serão essenciais: a equivalência entre massa inercial e massa gravitacional e a generalização do princípio de relatividade. Isto porque, lembra o autor, se em todas as situações há matéria envolvida, a noção de movimento inercial da relatividade restrita só tem sentido localmente, o que conduz às equações da relatividade geral. Privilegiando uma interpretação bastante realista, o autor conclui que "o espaço-tempo atua sobre a matéria e a radiação ditando-lhes como elas se devem deslocar". Gostaríamos de observar que, à parte autores com S. Weinberg ${ }^{3}$ negarem uma interpretação realista da relatividade geral, não devemos esquecer que a estrutura do espaço-tempo, mesmo numa interpretação realista, é dada pela distribuição de massa no universo, o que, aliás, Videira observa em uma passagem posterior (p. 81) àquela citada acima.

$\mathrm{O}$ autor conclui seu artigo observando que, embora a teoria da relatividade geral continue válida em escalas macroscópicas, uma unificação com a teoria quântica permanece como um desafio. Uma observação histórica que nos parece importante para aqueles que conhecem um pouco menos a história da física: segundo o autor, "no final

3 Gravitation and cosmology: principles and applications of the general theory of relativity. New York: John Wiley \& Sons, 1972 , p. 147 . 
do século XIX, a física consistia essencialmente da mecânica de Newton - satisfeita pelas massas - e do eletromagnetismo de Maxwell - satisfeito pelas cargas". Ora, é importante observar que não somente os princípios da termodinâmica já haviam sido estabelecidos - aliás, Einstein os cita como constituindo um certo modelo de teoria física - , mas esse domínio exibia alguns resultados e enunciava certos conceitos, como o de entropia, que não dependiam da mecânica newtoniana, apesar dos inúmeros esforços que foram feitos em favor de uma redução.

O quinto artigo, escrito por Luiz Davidovich, retoma o problema das contribuições de Einstein à teoria quântica. Davidovich lembra, logo no início do seu texto, que, dentre os famosos artigos de 1905, Einstein considera como o mais revolucionário aquele que propõe o quanta de luz. Mas a adesão do cientista alemão não foi tão imediata à sua própria formulação: a luz se comportaria "como se" fosse constituída de unidades elementares de energia. A resistência não era apenas de Einstein, pois toda a comunidade científica da época manifestava sua dúvida quanto a essa hipótese; um dos aspectos dessa teoria, a dependência linear da energia com a freqüência, só foi confirmada experimentalmente 10 anos depois. Como já foi apontado por M. Paty, a contribuição de Einstein à teoria quântica não se limitou ao artigo de 1905. Já em 1907, ele publica dois artigos sobre o calor específico dos sólidos, empregando a hipótese de Planck de quantização dos osciladores materiais, mostrando assim que o calor específico se anula quando a temperatura se aproxima do zero absoluto, além de explicar o valor anormalmente baixo do calor específico do diamante, até então não compreendido.

Em 1909, Einstein retorna a seus estudos sobre os fenômenos quânticos, quando examina as flutuações de energia da luz emitida por um corpo negro. Sua nova hipótese é que há dois tipos de contribuição para essas flutuações: uma delas associa-se ao caráter ondulatório da luz e a outra ao caráter corpuscular. Como observa Davidovich, muitos anos antes do conceito de complementariedade de Bohr, Einstein propõe o conceito da dualidade onda-partícula. Gostaríamos de remeter o leitor ao artigo de M. Paty: a teoria deve efetivamente levar em conta a especificidade do fenômeno estudado, mesmo que isso leve a conflitos conceituais momentâneos, como nesse caso.

Em 1916 e 1917, Einstein publica três artigos que tratam dos processos de emissão e absorção da radiação e associa, pela primeira vez, um momentum ao fóton. No artigo de 1917, ele percebe um problema conceitual profundo que se inicia na teoria quântica: o caráter probabilístico da nova teoria. Um dos aspectos que o incomodava, gostaríamos de sublinhar, tinha um componente filosófico que lhe era caro: as teorias físicas podem prescindir da causalidade? O “resíduo estatístico permanecerá?", pergunta ele. Em 1924 e 1925, Einstein encerra suas contribuições diretas à física quântica (ver, no entanto, adiante o problema do paradoxo EPR), não sem revelar a marca de seu estilo, e propõe a teoria que determinaria a condensação que ficou conhecida como 
Bose-Einstein. Segundo essa teoria - que tinha como base uma dedução da fórmula de Planck feita pelo físico S. N. Bose -, para temperaturas suficientemente baixas, um número crescente de moléculas ocupa o estado de energia mais baixa do gás, ocorrendo assim uma separação do conjunto de moléculas em duas partes: uma que se condensa e outra que permanece um gás ideal. Os estudos de Einstein sobre o mundo microscópico têm momentos bastante decisivos. O principal deles, ocorrido também nessa época, quando N. Bohr, H. Kramers e J. Slater propõem a famosa teoria BKS, que abre mão dos princípios de conservação de energia e do momentum em processos quânticos individuais, privilegiando o aspecto ondulatório. Esses princípios, segundo os autores, seriam o resultado de uma média estatística. Em 1925, quando Einstein fazia sua viagem à América Latina, Bothe e Geiger realizaram uma série de experimentos evidenciando o caráter corpuscular da radiação, sepultando a explicação exclusivamente ondulatória e reforçando, indiretamente, a concepção einsteiniana da manutenção dos dois princípios de conservação em todos os domínios físicos.

Davidovich conclui seu artigo com um breve histórico sobre o desenvolvimento da teoria quântica após os últimos artigos de Einstein sobre o tema. De 1925 até os nossos dias, vemos um crescente acordo da teoria quântica com os experimentos, mesmo em domínios problematizados por Einstein em 1935, que deram origem ao famoso paradoxo do argumento EPR e ao famoso teorema de Bell. Há ainda conceitos como o de superposição coerente, quando uma partícula quântica ocupa, ao mesmo tempo, duas regiões distintas, confirmado recentemente: experimentos realizados em 1996, inclusive com a participação do autor do artigo, conseguiram aprisionar um átomo em uma armadilha magnética em duas posições distintas ao mesmo tempo. Considerando, por um lado, a defesa intransigente da causalidade defendida por Einstein e, por outro lado, levando em conta seu reconhecimento dos resultados experimentais, é difícil inferir quais seriam as suas considerações sobre tais fenômenos. Certamente, elas não seriam triviais...

Saulo Carneiro nos apresenta, no sexto artigo, um dos aspectos mais conhecidos dos trabalhos de Einstein pelo grande público: suas concepções cosmológicas. No entanto, o histórico apresentado pelo autor é estimulante o bastante para segui-lo. Como lembra Carneiro, o interesse primeiro de Einstein não era cosmológico e o caminho por ele percorrido foi inverso ao de Galileu, que partiu de problemas astronômicos para a construção de uma física terrestre. Mas o autor observa que Einstein certamente inspirou-se em problemas cosmológicos, como a crítica do filósofo e físico austríaco E. Mach. Além disso, notaríamos que a teoria da relatividade geral leva naturalmente a problemas cosmológicos, pois se aplica a todo o universo. De fato, conforme apontado por Carneiro, dois anos após a formulação dessa teoria, Einstein propõe o primeiro modelo cosmológico. 
As críticas de Mach à teoria newtoniana da gravitação voltam-se inicialmente para o conceito de sistema inercial, que não estava previamente definido. Outra crítica diz respeito ao caráter absoluto das acelerações, que Newton postula - pode-se entender o argumento newtoniano recorrendo à situação em que um observador no interior de um trem vê um pêndulo sair da posição de repouso para uma posição inclinada, como resultado do movimento acelerado. Para Mach, o espaço e o tempo não poderiam ter existência e propriedades independentes de toda a matéria do universo.

É bem conhecido que essas idéias influenciaram Einstein em seu questionamento da gravitação newtoniana. Incorporadas ao princípio de equivalência entre massa inercial e gravitacional, as críticas de Mach são importantes para a edificação da teoria da relatividade geral. Observaríamos, no entanto, que não se pode esquecer o papel crucial desempenhado pela teoria da relatividade restrita, pois a teoria proposta em 1915 é uma clara generalização desta.

O modelo cosmológico proposto por Einstein resolveu um antigo problema conhecido como paradoxo de Olber. Segundo esse paradoxo, se o universo é infinito hipótese contestada pela relatividade geral -, o céu noturno seria tão claro como o céu diurno, pois as estrelas preencheriam todo o universo. Mas o universo oriundo do primeiro modelo cosmológico de Einstein era estático, o que o obrigou a adicionar um termo conhecido como "termo cosmológico" ou "constante cosmológica". Einstein o chamará de seu maior erro científico. No mesmo ano de 1917, o astrônomo e matemático holandês W. de Sitter propôs uma solução das equações da relatividade geral que admitia a propriedade de ser vazio, mas com curvatura não nula. Einstein considerou essa solução matematicamente correta, mas fisicamente inconsistente, pois havia uma singularidade nas equações. O problema levou a uma das maiores realizações da cosmologia do século xx: em 1925, o padre G. Lemaître, através de uma transformação adequada, mostrou que o universo proposto por de Sitter é um universo homogêneo em expansão; o afastamento das galáxias já conhecido à época corroborou fortemente a teoria. Um pouco antes, em 1922 e 1924, A. Friedman apresentou soluções não-estáticas das equações de Einstein e, também nesse modelo, o universo estaria em expansão. Desses dois trabalhos, a noção de um universo em expansão tornou-se um fato da cosmologia do século xx. Contudo, Carneiro observa, concluindo seu artigo, que os modelos mais recentes que descrevem o universo adotam algo como um termo cosmológico. Ao final, parece que mais uma vez Einstein acertou!

A atuação política de Einstein é o tema do artigo seguinte, de Olival Freire Júnior, que escolhe uma abordagem original: examina a defesa feita por Einstein em prol das liberdades civis nos EUA, entre o final da Segunda Guerra até a sua morte. Como o autor afirma, não tratará diretamente da faceta política mais conhecida de Einstein, que é a cooperação entre os povos, os direitos do povo judeu, a luta antinazista e o pacifismo. 
A defesa de Einstein pelas liberdades civis nos Estados Unidos insere-se num ambiente de perseguição do governo americano ao pensamento crítico, particularmente aos comunistas, o que significava, de uma forma geral, uma ameaça às próprias liberdades civis. É nesse contexto que Einstein escreve cartas aos envolvidos em processos de intimação expedidos por órgãos policiais e por comissões do Senado e aconselha os intelectuais a se recusarem a depor, mesmo sabendo que isso poderia ter conseqüências nefastas para o próprio bem-estar desses intelectuais. "Francamente - escreve ele a um professor secundário intimado a depor -, eu só vejo o caminho revolucionário da não-cooperação, no sentido de Gandhi. Todo intelectual intimado por um desses comitês deveria recusar-se a testemunhar, isto é, deve estar preparado para a prisão e para a ruína econômica, em suma, para o sacrifício de seu bem-estar pessoal, no interesse do bem-estar cultural do país”.

A defesa de Einstein das liberdades civis contempla um episódio significativo para a história do Brasil. D. Bohm era professor da Universidade Princeton e foi intimado a depor, em 1949, por suas ligações com o Partido Comunista. Tendo se recusado a responder ao interrogatório, foi preso por desacato ao Congresso. Certamente por causa desse episódio, a Universidade decidiu não renovar o seu contrato. Mesmo com a intervenção de Einstein, Bohm não mais conseguiu trabalho nos Estados Unidos. O físico J. Tiomno, que concluía seu doutorado naquela universidade, convidou-o a vir ao Brasil. Bohm recebeu o apoio de Einstein, que chegou a escrever cartas em sua defesa endereçadas a Getúlio Vargas e a Adhemar de Barros. Esse episódio é também notável pelos depoimentos de Bohm sobre a corrupção no país, bem como sobre o incipiente desenvolvimento da ciência brasileira na época.

Finalizando seu artigo, Freire relata um episódio surpreendente. O chefe do FBI no início da década de 1950, J. E. Hoover, montou um dossiê sobre Einstein buscando provar que o cientista seria comunista e/ou espião do governo soviético. Além do fato de Einstein ser um cientista eminente, o que levou Hoover a conduzir a investigação no mais absoluto sigilo, o FBI nada encontrou que provasse a denúncia; finalmente a insatisfação dentro e fora dos EUA com a histeria macartista, além do agravamento de saúde de Einstein, levou ao arquivamento do processo. À parte o lado inegavelmente policialesco do dossiê, há revelações importantes, como a luta de Einstein contra a discriminação racial sofrida pelos negros norte-americanos, o que resultou em relações de amizade de Einstein com personalidades negras como o historiador W. E. du Bois e com o ator, cantor e ativista político P. Robeson.

Olival Freire encerra seu artigo fazendo um paralelo entre a época de Einstein e a atual situação política dos EUA, depois do ataque terrorista de 11 de setembro de 2001 . Após esse episódio, o governo Bush tem interferido diretamente na pesquisa científica, além de colocar, em conselhos e consultorias das agências federais ligadas à ciência, 
cientistas que se destacam não por seus méritos, mas por seu alinhamento às posições conservadoras do governo. No dia 10 de novembro de 2004, o jornal The New York Times alertava para o fato de oito jornalistas estarem sendo processados e na iminência de serem presos porque têm-se recusado a revelar as fontes de matérias incômodas a setores da administração Bush. "Einstein precisaria escrever uma nova carta [...], desta vez dirigida aos jornalistas norte-americanos", conclui Freire.

O oitavo artigo é escrito por Ildeu de Castro Moreira e por Nelson Stuart. Os autores abordam um tema muito pouco examinado: os trabalhos de divulgação científica de Einstein. Eles lembram que a divulgação científica tem sido feita por cientistas importantes ao longo da história da ciência, a partir de Galileu, passando por Kepler e Hooke, entre outros. Parece ser possível concluir, da exposição de Moreira e Stuart, que os grandes cientistas necessitam, de certa forma, expor suas idéias ao grande público, pois, mesmo recentemente, os criadores da mecânica quântica - Planck, Bohr, Born, Schrödinger, Heisenberg e Dirac - escreveram livros e artigos de divulgação. Mais próximos de nós, Hawking, Penrose, Gellman, Weinberg, entre outros, apresentam uma produção importante também quando se fala em divulgação científica. Einstein é um caso bastante ilustrativo, tendo em vista que não somente redigiu numerosos trabalhos para o público não especializado, mas também proferiu muitas palestras, explicando seus trabalhos em muitos países, incluindo o Brasil. Dentre esses trabalhos, pode-se destacar o seu livro Teoria da relatividade especial e geral (uma exposição popular), publicada já em 1916, logo após a formulação definitiva da relatividade geral, e o livro Evolução da física, de 1938, escrito com L. Infeld. Vale observar que, em um artigo de 1919, Einstein ressalta um aspecto relevante para a filosofia da ciência, classificando as teorias científicas em dois grupos. No primeiro grupo, estariam as teorias "construtivas" - que hoje diríamos que fazem uso de modelos - e, no segundo, as teorias baseadas em princípios, onde se enquadra a relatividade.

Pode-se perguntar qual é o valor do trabalho de divulgação científica. Os autores não fazem diretamente essa pergunta, mas poderíamos dizer que, como escreveu Einstein em seu Evolução da física, "nenhum cientista pensa por fórmulas". Dessa maneira, é possível acompanhar, ao menos em parte, como se desenvolveu certa idéia, como foi edificado certo conceito ou então como eles se articulam logicamente. Também parece possível afirmar que o trabalho de divulgação científica permite perceber, ou mesmo explicitar, os objetivos dos cientistas. Em seu Evolução da física, um conceito caro a Einstein é o de campo. Ele pergunta:

não poderíamos rejeitar o conceito de matéria e construir uma física puramente de campo? O que impressiona nossos sentidos é, na realidade, uma grande concentração de energia em espaço relativamente pequeno. Poderíamos considerar 
a matéria como sendo as regiões do espaço em que o campo é extremamente forte. Dessa maneira, poderia ser criada uma nova base filosófica.

Esse programa científico-filosófico ainda se encontra aberto.

No artigo seguinte, Ildeu Moreira examina com bastante detalhe a disputa entre Einstein e Bohr, apontada no quinto artigo, mas desta feita da perspectiva da visita de Einstein ao Brasil. Isso porque Einstein proferiu uma palestra no Brasil após conhecer os resultados da experiência de Bothe e Geiger, também já apontada acima. O artigo tem um grande valor histórico, pois reproduz os trechos mais importantes do discurso de Einstein na Academia Brasileira de Ciências. Nele, vê-se o quanto Einstein estava convencido do caráter corpuscular da luz, o que as experiências vieram a confirmar.

O décimo artigo, de Antonio Augusto Passos Videira, também examina a visita de Einstein ao Brasil. O autor aponta as possíveis razões de porque Einstein teria aceitado visitar o país, pois essa estadia não estava inicialmente prevista. As razões seriam basicamente duas: um certo agradecimento ao país pela expedição de 1919, em Sobral, que confirmou aspectos importantes da relatividade geral e, principalmente, um apoio à comunidade científica, pois a visita do mais notável físico do século xx ao país mostraria a importância da ciência básica, em grandes dificuldades, desde aquela época. Embora Einstein tenha se mostrado bastante solícito e educado, fica claro que não teve, de uma maneira geral, uma boa impressão das pessoas ("são, em sua maioria, vazias e pouco interessantes", comenta ele em uma carta a M. Besso). "Todos dão uma impressão tropical amolecida", escreveu Einstein em seu diário. "De que valem a beleza natural e a riqueza?", pergunta Einstein. A resposta não nos é muito favorável: "Eu penso que a vida de um escravo do trabalho europeu ainda seja mais rica, sobretudo menos utópica e nebulosa". Videira imputa a má impressão de Einstein acerca do Brasil ao exíguo tempo de permanência do cientista no país. De toda maneira, a visita pretendeu afirmar, tanto do lado brasileiro, quanto do de Einstein, uma certa maturidade da comunidade científica brasileira.

O último artigo, de Henrique Fleming, reproduz os principais trechos da troca de correspondência entre Einstein e seu amigo M. Besso. Fleming nota que, como o próprio Einstein reconheceu, Besso possuía uma grande capacidade intelectual, mas preferiu uma espécie de renúncia a favor do "amigo genial", fornecendo-lhe "vagares e paz de espírito" para que pudesse exercer sua genialidade em condições bastante satisfatórias.

A troca de cartas entre os dois amigos, além de conferir um lado mais humano a uma figura mítica do mundo da ciência, revela também, com detalhes, o processo de gestação de muitos trabalhos importantes de Einstein, particularmente o das duas teorias da relatividade e da teoria quântica. Besso foi um amigo devotado até o final de sua vida. Respondendo a uma pergunta do filho do amigo - "se meu pai era tão dotado como 
o senhor tem a gentileza de me dizer, por que não deixou uma obra comensurável com essa grandeza?", Einstein faz uma enunciação emblemática: "porque lhe faltava uma coisa só, que eu e meus colegas temos a desmesura: a ambição”. Mas como Einstein revela na última carta escrita aos familiares de Besso, a razão poderia estar em seus interesses: "o círculo de seus interesses, escreve Einstein referindo-se ao amigo já falecido, parecia verdadeiramente sem limites. Todavia, eram as preocupações críticofilosóficas que pareciam importar-lhe mais". Suas palavras finais na mesma carta são agora de um físico que penetrou nos segredos mais profundos da natureza: "Eis que, de novo, ele me precede de pouco, deixando este estranho mundo. Isto nada significa. Para nós, físicos crentes, esta separação entre passado, presente e futuro não tem senão o valor de uma ilusão, por tenaz que seja”. Menos de um mês depois, Einstein morre.

A série de artigos é encerrada com uma cronologia sobre a vida de Einstein, que vale a pena ser lida. Vemos um cientista em grande atividade intelectual, não apenas na física, mas em outros setores, incluindo trocas de cartas com o psicanalista S. Freud, com o filósofo inglês B. Russell e uma atividade política importante em defesa de causas pacifistas, do povo judeu, das liberdades civis, além de uma vida pessoal conturbada. Dois casamentos, uma filha da qual não se soube mais o paradeiro, um filho que morreu num hospital psiquiátrico na Suíça e alguns sérios problemas de saúde, vindo a falecer em 1955 em decorrência de um deles. A cronologia mostra os principais fatos da vida pessoal, científica e intelectual de Einstein, mas apresenta outros bem pouco conhecidos, como o concerto em que ele toca seu violino - deixado para o neto - e cuja arrecadação foi destinada aos refugiados alemães da Segunda Guerra.

Algumas considerações à guisa de conclusão. Não há dúvida de que Einstein foi um homem dedicado quase integralmente à ciência, à física em especial, um pacifista e um irredutível defensor dos direitos humanos e da liberdade de pensamento. No que se refere ao método, aspecto nem sempre tão contemplado na análise dos seus trabalhos, parece ser possível destacar a defesa de certos pressupostos filosóficos, como o da causalidade como algo essencial para compreender o mundo natural. Aliada a essa defesa da causalidade, a busca da relação mais adequada possível entre teoria e experiência mostrava-se como um guia seguro para o trabalho em ciência, mas a teoria terminava por definir os contornos dessa adequação, para determinar - parafraseando Galileu - como o mundo estava escrito. Poucos físicos chegaram tão próximo de compreender a "escrita" do Criador.

Samuel Simon Professor Doutor do Departamento de Filosofia da Universidade de Brasília. samuell@unb.br 